\title{
As obrigações processuais penais positivas segundo os precedentes das cortes europeia e interamericana de direitos humanos ${ }^{1}$
}

Frederico Valdez Pereira ${ }^{2}$

Douglas Fischer ${ }^{3}$

\section{RESUMO}

Procurar-se-á demonstrar que há inúmeros precedentes das Cortes supranacionais de direitos humanos que, por interpretação das respectivas convenções (e como decorrência também das próprias previsões constitucionais internas), reconhecem a existência de expressas obrigações processuais penais positivas que consistem, em verdade, no dever de os Estados partes de adotar todas as providências necessárias e adequadas para a apuração dos fatos ilícitos cometidos (obrigação de meio), sempre respeitando-se (busca do equilíbrio) os direitos fundamentais dos investigados/processados (obrigações de resultado). A finalidade é demonstrar que os precedentes reconhecem de forma muito clara e unânime que, no âmbito da proteção dos direitos humanos (com repercussões obviamente no âmbito das investigações e processamento penal dos eventuais infratores), é fundamental considerar também o plexo de garantias protegidos das vítimas e da coletividade em geral.

1 Data de recebimento: 17/02/2018. Data de aceite: 10/05/2019.

2 Juiz Federal, Doutorando em Processo Penal na Università degli Studi de Pavia/Itália, Mestre em Direito pena Universidade de Lisboa/Portugal, Especialista em Direito Penal Econômico pela Unisinos/ RS, Professor de Direito Processual Penal.

3 Procurador Regional da República na $4^{a}$ Região, Mestre em Instituições de Direito e do Estado pela PUCRS, Professor de Direito Penal e Direito Processual Penal. E-mail: douglas@mpf.mp.br 
Palavras-chave: Obrigações processuais penais positivas. Cortes supranacionais de direitos humanos. Direitos fundamentais.

\section{INTRODUÇÃO}

O presente texto tem sua origem na obra As Obrigações Processuais Penais Positivas segundo as Cortes Europeia e Interamericana de Direitos Humanos, ${ }^{4}$ publicada em março de 2018. A finalidade é apresentar uma síntese das principais ideias desenvolvidas na referida obra, daí a razão de muitas expressas citações no corpo do texto, procurando-se manter a originalidade do que defendido.

Em resumo, procurar-se-á demonstrar que há inúmeros precedentes das Cortes supranacionais de direitos humanos que, por interpretação das respectivas convenções (e como decorrência também das próprias previsões constitucionais internas), reconhecem a existência de expressas obrigações processuais penais positivas que consistem, em verdade, no dever de os Estados partes de adotar todas as providências necessárias e adequadas para a apuração dos fatos ilícitos cometidos (obrigação de meio), sempre respeitando-se (busca do equilíbrio) os direitos fundamentais dos investigados/ processados (obrigações de resultado). A finalidade é demonstrar que os precedentes reconhecem de forma muito clara e unânime que, no âmbito da proteção dos direitos humanos (com repercussões obviamente no âmbito das investigações e processamento penal dos eventuais infratores), é fundamental considerar também o plexo de garantias protegidos das vítimas e da coletividade em geral.

4 Pereira, Frederico Valdez; Fischer, Douglas. As Obrigações Processuais Penais Positivas Segundo as Cortes Europeia e Interamericana de Direitos Humanos. Porto Alegre: Livraria do Advogado, 2018. 


\section{O GARANTISMO PENAL INTEGRAL}

Antes de adentrar na compreensão do tema central das obrigações processuais penais positivas, fundamental uma breve incursão no tema do garantismo penal integral ${ }^{5}$. Conforme destacamos na obra, o tema do garantismo ainda traz muitas discussões, especialmente porque, compreendemos, de um modo geral na América Latina (mas especialmente no Brasil), que o pensamento atrelado às ideias filosóficas do Professor Luigi Ferrajoli merece uma devida análise crítica e, sobretudo, uma contextualização histórica. Reafirmamos incondicionalmente que aderimos a muitas de suas ideias, mas, como se verá mais adiante, o garantismo é dinâmico, uma "obra inacabada", que está, em verdade, em constante aperfeiçoamento. Exatamente por isso é que se defende que o garantismo deva ser compreendido de forma integral, não apenas pelo prisma originário de defesa exclusiva de direitos fundamentais de primeira geração, de imposição de limites de atuação do Estado.

A compreensão de que o garantismo deveria proteger exclusivamente direitos fundamentais de primeira geração tem gerado, em nossa compreensão, verdadeira desproteção sistêmica. É dizer: sem racionalidade (para não dizer sem fundamentação), protegem-se exclusivamente direitos individuais fundamentais, sem que se note uma consideração dos demais direitos fundamentais que formam a complexa teia de bens e valores que possuem proteção constitucional.

\footnotetext{
5 Sintetizando,[...], embora construídos por premissas e prismas um pouco diversos, o princípio da proporcionalidade (em seus dois parâmetros: o que não ultrapassar as balizas do excesso e da deficiência é proporcional) e a teoria do garantismo penal integral (em nossa compreensão) expressam a mesma preocupação: o equilíbrio na proteção de todos (individuais ou coletivos) direitos e deveres fundamentais expressos na Carta Maior. Quer-se dizer com isso que, em nossa compreensão (integral) dos postulados garantistas, o Estado deve levar em conta que, na aplicação dos direitos fundamentais (individuais e sociais), há a necessidade de garantir também ao cidadão a eficiência e segurança, evitando-se a impunidade. O dever de garantir a segurança não está em apenas evitar condutas criminosas que atinjam direitos fundamentais de terceiros, mas também (segundo pensamos) na devida apuração (com respeito aos direitos dos investigados ou processados) do ato ilícito, e, em sendo o caso, da punição do responsável. Fischer, Douglas. Garantismo penal integral [ ] e o Princípio da Proporcionalidade: breves anotações de compreensão e aproximação dos seus ideais. Revista de Doutrina 4. Região, v. 28, p. 1, 2009. Também em Revista do Núcleo Criminal da PRR $1^{\text {a }}$ Região - Brasília, v. Ano 2, p. 16-17, 2009. Também em Revista de Doutrina 4. Região, v. 28, p. 1, 2009.
} 
Como salienta Prieto Sanchís, Ferrajoli sempre insistiu que o paradigma garantista

es uno y el mismo que el actual Estado constitucional de derecho, o en que representa la outra cara del constitucionalismo, concretamente aquella que se encarga de formular las técnicas de garantías idoneas para asegurar el máximo grado de efectividad a los derechos [...] [todos os direitos, explicitamos] [...] reconocidos constitucionalmente. Prieto Sanchís (2005).

Desde já é importante destacar que existem

garantías positivas y garantías negativas; las primeras obligarían a abstenciones por parte del Estado y de los particulares en respeto de algun derecho fundamental, mientras que las segundas generarían obligaciones de actuar positivamente para cumplir con la expectativa que derive de algun derecho. Carbonell (2005, p. 182).

A equação pode parecer complexa, mas na raiz é bastante simples: para a (e na) proteção dos direitos e das garantias fundamentais (individuais e coletivos) e na exigibilidade do cumprimento dos deveres fundamentais, há se observar que os princípios elencados funcionam como guias na dinâmica e harmônica configuração (na melhor medida possível) de todos os bens e valores protegidos constitucionalmente.

Adolfo Bidart (2006) é preciso quando sustenta que

'la mera formulación de los derechos humanos' (...) revela la necesidad de su complementación con los deberes humanos, que tienen igual significación y trascendencia que aquellos con los que mutuamente se deslindan y garantizan en su ejercicio o realización. Los derechos humanos en cada hombre requieren, para su efectiva existencia, igual fundamento o base, de deberes de igual jerarquía e significación.

A Constituição Federal brasileira é (integralmente, segundo nossa expressão) garantista, e assenta seus pilares nos princípios 
ordenadores de um Estado Social e Democrático de Direito, mas insistimos no sentido de que a teoria garantista não existe apenas para proteção exclusivamente de interesses e direitos fundamentais individuais.

Se a Constituição é o ponto de partida para (também) a análise (vertical) do influxo dos princípios fundamentais de natureza penal e processual penal, decorre daí que o processo hermenêutico não poderá assentar-se sobre fórmulas rígidas e pela simples análise pura (muito menos literal) dos textos dos dispositivos legais (inclusive da própria Constituição).

A compreensão e a defesa dos ordenamentos penal e processual penal também reclamam uma interpretação sistemática (por isso integral) dos princípios, das regras e dos valores constitucionais para tentar justificar que, a partir da Constituição Federal de 1988 (o novo marco teórico que referimos inicialmente), há também novos paradigmas influentes também (ao que interesse precipuamente aqui) em matéria penal e processual penal. Diante de uma Constituição que preveja, explícita ou implicitamente, a necessidade de proteção de bens jurídicos (individuais e coletivos) e de proteção ativa dos interesses da sociedade e dos investigados e/ou processados, incumbe o dever de se visualizar os contornos integrais do sistema garantista.

De relevo o que diz Perfecto Andrés Ibáñez, para quem se deve analisar a existência atualmente de um "garantismo dinámico, que es el que trasciende el marco de o proceso penal y también el de la mera garantía individual de carácter reactivo para ampliarse al asegurarmiento de otros derechos e de los correspondientes espacios hábiles para su ejercicio".

Bastante incisiva e objetiva, a advertência de Miguel Carbonell (2005, p. 171) é no sentido de que a teoria garantista de Luigi Ferrajoli apresenta-se como um paradigma inacabado, como uma obra no meio do caminho, carente de complementação e devida 
compreensão (Ibid., p.171). E realmente é inacabado, pois seria impossível conceber-se ideais desse jaez estanques no tempo e no espaço, sem a devida contextualização na realidade atual, que gera um constante (re)ajuste de todos os valores protegidos constitucionalmente. A sua base "sobretudo por razões históricas" é fundamental. Mas demanda a devida adaptação.

De certa, forma Ferrajoli parece aceitar a crítica construtiva de Carbonell, ao admitir expressamente que "el paradigma garantista puede expandirse (y en el plano normativo ha ido efectivamente expandiéndose) en tres direcciones: hacia la tutela de los derechos sociales y no solo de los derechos de libertad, frente a los poderes privados y no solo a los poderes públicos y en ámbito internacional y nó solo estatal" (FERRAJOLI, 2006, p. 113).

Compreendemos que todos os direitos fundamentais equivalem a vínculos de substância, que, por sua vez, condicionam a validez da essência das normas produzidas (e também nas suas aplicações), expressando, ao mesmo tempo, os fins aos quais está orientado o denominado Estado Constitucional de Direito (FERRAJOLI, 2004, p. 152).

Assim, se todos os Poderes estão vinculados a esses paradigmas "como de fato estão", especialmente é o Poder Judiciário quem tem o dever de dar garantia também aos cidadãos (sem descurar da necessária proteção dos interesses sociais e coletivos) diante das eventuais violações que eles vierem a sofrer. É exatamente por isso que Miguel Carbonell refere que "en el modelo del Estado social los poderes públicos dejan de ser percibidos como enemigos de los derechos fundamentales y comienzan a tomar, por el contrario, el papel de promotores de esos derechos, sobre todo de los de caracter social". Carbonell (2005, p. 179).

Em nossa compreensão (integral) dos postulados garantistas, o Estado deve levar em conta que, na aplicação dos direitos fundamentais (individuais e sociais), há a necessidade de garantir 
também ao cidadão a eficiência e segurança.

Como mais um imperativo constitucional (art. 144, caput, CF), o dever de garantir segurança (que se desdobra em direitos subjetivos individuais e coletivos) não está em apenas evitar condutas criminosas que atinjam direitos fundamentais de terceiros, mas também na devida apuração (com respeito aos direitos dos investigados ou processados) do ato ilícito e, em sendo o caso, da punição do responsável. Nesse diapasão, calham ao caso novamente as considerações de Miguel Carbonell, quando assenta que

la obligación de proteger significa que el Estado debe adoptar medidas destinadas a evitar que otros agentes o sujetos violen los derechos sociales, lo que incluye mecanismos no solamente reactivos frente a las violaciones [...], sino también esquemas de carácter preventivo que eviten que agentes privados pudean hacerse con el control de los recursos necesarios para la realización de un derecho. Carbonell (2005, p. 194).

Especialmente em terras brasileiras, é preciso reafirmar a premissa de que os direitos fundamentais não contêm apenas uma proibição de intervenção, possuindo também o denominado postulado de proteção. Como reconhece Canaris, não existe unicamente uma proibição de excesso (Übermassverbot), mas também uma proibição de omissão (Untermassverbot). Enquanto a Proibição de Excesso (übermaBverbot) depende da aferição de estar sendo restringido excessivamente um direito fundamental (especialmente os de primeira geração), a Proibição de Proteção Deficiente (untermaBverbot) está em se apurar quando direitos fundamentais - em face de condutas (notadamente criminais) que os atinjam - não estão sendo suficientemente protegidos, ou ainda, quando se está afastando indevidamente o cumprimento dos deveres fundamentais.

Em complementação, é exatamente o que diz Carlos Bernal Pulido, quando destaca que 
la cláusula del Estado social de derecho modifica el contenido que los derechos fundamentales tenían en el Estado liberal. [ ] De este modo, junto a la tradicional dimensión de derechos de defensa, que impone al Estado el deber de no lesionar la esfera de libertad constitucionalmente protegida, se genera un nuevo tipo de vinculación, la vinculación positiva. En esta segunda dimensión, los derechos fundamentales imponen al Estado un conjunto de "deberes de protección" [dizemos nós: de proteção ótima] que encarnan en conjunto el deber de contribuir a la efectividad de tales derechos y de los valores que representan. Bernal Pulido (2005, p.126).

Na sequência de sua doutrina ${ }^{6}$, destacando que "el efecto disuasorio o preventivo de la pena es una de las estrategias más efectivas para proteger los derechos fundamentales de ataques provenientes de terceros", enfatiza que

el principio de proporcionalidad supone también interpretar los derechos fundamentales de protección como principios y aceptar que de ellos se deriva la pretensión prima facie de que el legislador los garantice en la mayor medida posible, habida cuenta de las posibilidades jurídicas y fácticas. Esto quiere decir que estos derechos imponen prima facie al legislador el desarrollo de todas las acciones (no redundantes) que favorezcan la protección de su objeto normativo, y que no impliquen la vulneración de otros derechos e principios que juegen en sentido contrario. [ ] La versión del principio de proporcionalidad que se aplica frente a los derechos de protección se llama prohibición de protección deficiente (el Untermassverbot) de la doctrina alemana. Este principio se aplica para determinar si las omisones legislativas, que no ofrecen un máximo nivel de aseguramiento de los derechos de protección, constituyen violaciones de estos derechos. Cuando se interpretan como principios, los derechos de protección implican que el legislador les otorgue prima facie la máxima protección. Si éste no es el caso, y, por el contrario, el legislador protege un derecho sólo de manera parcial o elude brindarle toda protección, la falta de protección óptima deve enjuiciarse entonces desde el punto de vista constitucional mediante la prohibición de protección deficiente. [...] Bernal Pulilo (Ibid., pp. 139-142).

6 Aplicável integralmente não só ao controle das ações do legislador, mas a todos os Poderes. 
De igual modo, complementamos, é dever de todos os Poderes vinculados à existência de um Estado Social e Democrático de Direito a adoção de todos os meios que, sem desproteger direitos fundamentais de primeira geração (garantismo negativo), maximizem a proteção dos demais direitos e deveres impostos constitucionalmente como essenciais, equilibrando-se a balança do sistema por intermédio do denominado garantismo positivo. Noutras palavras, o garantismo positivo se caracteriza como um dever de proteção (de ação) que implica a obrigação de o Estado, nos casos em que for necessário, adequado e proporcional em sentido estrito, restringir direitos fundamentais individuais dos cidadãos (embora, repise-se, a teoria garantista na ideia de Ferrajoli não se pauta por análise dos subprincípios da "proporcionalidade"). Portanto, é fundamental compreender que o conteúdo objetivo dos direitos fundamentais permitiu também a elaboração dos deveres de proteção, justificando a obrigação de o Estado assegurar a proteção de bens jurídicos por meio de medidas legislativas e operacionais, portanto, exigindo uma ação positiva estatal (PREREIRA; FISCHER, 2018, p.33).

\section{Já dissemos anteriormente que}

quando se defende que sejam aplicados na íntegra e de forma concatenada os postulados constitucionais, está-se procurando demonstrar que o garantismo nada mais é do que a visão atual do constitucionalismo (exatamente como reconhece Ferrajoli): há se considerar na hermenêutica constitucional (sobretudo com reflexos nas searas penal e processual penal) a valoração de todos os direitos e deveres existentes no corpo da Carta Maior, e não apenas os direitos fundamentais individuais (e de primeira geração) dos investigados e/ou processados criminalmente. ${ }^{7}$

\section{Assim, complementamos, "o que se pretende é buscar a com-}

7 No dia 16 de outubro de 2013, em evento organizado e realizado no Ministério da Justiça em Brasília, ao final de sua exposição, Ferrajoli foi indagado como poderia ser conformada ao garantismo a pretensão de punir agentes de repressão política por crimes cometidos no período da ditadura brasileira em razão do período já transcorrido até os dias atuais pela fluência da prescrição. De forma muito objetiva (mas sem surpresa para quem conhece a ideia central do garantismo em sua essência original), respondeu que seria perfeitamente possível a conformação (utilizando a expressão da indagação que lhe foi feita), pois o garantismo defendido por ele traz em seu bojo, à luz de (todos) princípios constitucionais vigentes e do Direito Internacional, a obrigação de o Estado agir (denominadas obrigações positivas) para punir, eficazmente, os autores dos crimes dessa natureza, não podendo serem invocadas regras de prescrição como forma a pretender afastar eventuais ações penais. Nessa linha, inclusive, em capítulo adiante visto será destacado o tema da prescrição à luz de cortes internacionais. 
preensão do garantismo penal que se considera mais adequada (e de algum modo recepcionada pelas Cortes Interamericana e Europeia de Direitos Humanos) pois, na senda de Larenz, a alternativa verdadeiro/falso é estranha ao Direito, em que existe apenas o aceitável (justificável)" (Ibid., 2018, p.29) e portando-se a Jorge Reis Novais (2003, p. 57), enfatizamos nossa compreensão de que

processo criminal e a respectiva imposição de pena aos infratores é uma forma de, mediante as irradiações dos efeitos da prevenção geral positiva, garantir a segurança e convivência entre os pares que não infringiram o ordenamento jurídico. Analisando o tema relacionado aos deveres de proteção e os direitos fundamentais, é possível inserir entre as mais relevantes elaborações nos Estados Sociais e Democráticos de Direito do pós-guerra a noção de que, para além de sua dimensão subjetiva, os direitos fundamentais constituem um sistema objetivo de valores que legitima a ordem jurídico-constitucional do Estado. (PREREIRA; FISCHER, 2018, p.29).

\section{OS MANDADOS DE PROTEÇÃO DE DIREITOS E DEVERES FUNDAMENTAIS À LUZ DA CONSTITUIÇÃO E DAS REGRAS CONVENCIONAIS}

Seguindo ainda na linha que argumentamos na obra originária do tema ora abordado (Ibid., 2018, p.40), segundo destaca Canotilho a abertura, incompletude e imperfeição são as características de uma Constituição (CANOTILHO, 2001, p. 116 e 88-9) (também do ordenamento convencional, dizemos nós), especialmente a "abertura material, a abertura ao tempo, que é um dos topoi centrais da moderna teoria da constituição". Ainda na senda de Canotilho, cumpre gizar que

uma das concepções que parece lograr mais sufrágios na moderna juspublicística é aquela que pretende conciliar a ideia de constituição com duas exigências fundamentais do Estado Democrático-Constitucional: (1) a legitimidade material, o que aponta para a necessidade de a lei fundamental transportar os princípios materiais caracterizadores do Es- 
tado e da sociedade; (2) a abertura constitucional, porque, não obstante a constituição ser uma ordem material, ela deve possibilitar o confronto e a luta política dos partidos e das forças políticas, portadoras de projectos alternativos de realização dos fins constitucionais.

Nessa mesma linha, é fundamental ter como concepção a doutrina de Coello Nuño (2005, p. 111, 116 e 290), que assenta que toda Constituição aberta que sempre será dinâmica devido ao necessário movimento da força das sociedades, cambiantes por natureza, e os conteúdos e valores constitucionais serão aperfeiçoados mediante a interpretação e aplicação do ordenamento maior.

Dizemos em complemento que "a constitucionalização somada à convencionalização dos princípios processuais de justiça exige significativa mudança na postura dogmática dos intérpretes e aplicadores do direito também no âmbito da análise sobre a organização do procedimento judicial", pois a "estrutura, as reformas e os temas relevantes do direito processual devem ser estudados a partir da interação entre os princípios e valores compartilhados constitucional e convencionalmente, inclusive, conforme adverte Trocker, permitindo o diálogo com a jurisprudência no terreno da legitimidade constitucional e convencional verificada em concreto". Mais especificamente no âmbito penal, "é necessário evidenciar de que forma a jurisprudência se orienta na tarefa de solucionar o conflito imanente entre indivíduo e autoridade, que se concreta no balanceamento do dever de garantir "l'inquisito e nel contempo la difesa sociale" (PREREIRA; FISCHER, 2018, p. 42).

Reafirmamos a compreensão de que não há dúvidas de ser necessário haver um modelo de processo penal justo, afinado e orientado pelos princípios e valores incidentes na equação da dinâmica processual. Porém - e aqui é o ponto fundamental compreender - é necessário que as lentes estejam focadas não apenas nas pautas normativas domésticas, restritas a um dado ordenamento jurídico. O foco deve-se ampliar de modo a contemplar 
as convenções e demais fontes supranacionais que tratam sobre direitos humanos e jurisdição penal. Assim, na "busca de soluções sistematicamente melhores, ao desenvolver a hierarquização dos princípios, regras e valores, o intérprete deve estar imbuído em seu espírito da prudência e da necessidade de agir com temperança", devendo também "considerar a premissa de que não existem princípios, regras ou valores absolutos, atentando para o fato de que essa relativização não significa debilidade, ao contrário, demonstra o fortalecimento mútuo dos princípios, bem como de suas dimensões" (Ibid., 2018, p. 43).

Diante de tais premissas, há se ver que as fontes normativas internacionais provenientes do sistema de tutela dos direitos humanos - o que inclui os aportes jurisprudenciais da Corte Interamericana para o caso do Brasil - devem ser utilizadas como cânones interpretativos do direito pátrio, gerando uma obrigação aos juízes domésticos de aplicarem o ordenamento jurídico interno de maneira conforme também ao direito supranacional, valorizando, assim, exegese normativa que preserve o Estado dos riscos de uma responsabilização internacional por descumprimento de obrigações daí decorrentes. Assim, uma "melhor interpretação" deve considerar todas as normas integradas entre si, não isoladas nem dispersas, compreendendo-se que todos os comandos nela insertos (unidade) estão costurados por fios seguros, e por isso suficientemente fortes para sustentar as tensões dialéticas que naturalmente dela defluem (pluralidade).

Exatamente por isso que sustentamos que os direitos e os deveres fundamentais possuem uma conexão indissociável.

Pouco considerados especialmente na doutrina nacional, os deveres fundamentais são objeto de incisiva advertência de Zagrebelsky, para quem "son los deberes de todos hacia los demás los que estan destinados a asentarse de una manera estable, como situación empírica permanente. En otras palabras, en las socie- 
dades justas la categoria dominante es la de los deberes, no la de los derechos" (2005, p. 95).

Segundo Casalta Nabais, os deveres fundamentais se caracterizam como deveres jurídicos do homem e do cidadão, que, por fixarem a posição fundamental do indivíduo, "têm especial significado para a comunidade e podem por esta ser exigidos" (NABAIS, 1998, p. 64). Portanto, enquanto os direitos fundamentais se traduzem em situação de prevalência do indivíduo face ao Estado (verdadeiras posições jurídicas ativas dos cidadãos em relação ao Estado ou comunidade), Nabais atribui uma função passiva aos deveres. Eles se apresentam como posições subjetivas, porque são atribuídos ao indivíduo pela própria Constituição, vinculados com a organização política e/ou econômica do Estado.

Tais como os direitos, os deveres fundamentais encontram seus suportes e suas justificativas nos princípios norteadores dos sistemas vigentes, notadamente o constitucional, que são os locais onde vêm expressos os valores de cada sociedade. Essa a razão pela qual sustentamos que vez por todas há de se superar a concepção tradicional (liberal) de que existem (unilateralmente) apenas direitos fundamentais de primeira geração. É preciso compreender também que os deveres fundamentais são, portanto, posições que se traduzem como quotas-partes constitucionalmente (por isso, deveres materialmente fundamentais) exigidas de cada um e, consequentemente, do conjunto dos cidadãos para o bem comum.

Como defende conclusivamente Nabais (embora tratando de tema específico, mas que é geral o suficiente para sua aplicação a todas as demais categorias),

não há direitos sem deveres, porque não há garantia jurídica ou fática dos direitos fundamentais sem o cumprimento dos deveres do homem e do cidadão indispensáveis à existência e funcionamento da comunidade estadual, sem a qual os direitos fundamentais não podem ser assegurados nem exercidos. E não há deveres sem direitos, porque é de todo inconcebível um estado de direito democrático 
assente num regime unilateral de deveres, já que contra ele se levantariam as mais elementares exigências de justiça e de respeito pelos direitos humanos, como demonstra à saciedade a específica dimensão histórica dessa fórmula, que simultaneamente teve por objectivo e constituiu a base fundamental da instituição do estado constitucional democrático [...] Em suma, os direitos e deveres fundamentais não constituem categorias totalmente separadas nem domínios sobrepostos, encontrando-se antes numa relação de 'conexão funcional', que, por um lado, impede o exclusivismo ou a unilateralidade dos direitos fundamentais, como em larga medida aconteceu durante a vigência do estado de direito liberal em que um tal entendimento tinha subjacente a concepção dualista do estado então dominante e, por outro lado, não constitui obstáculo à garantia da primazia ou primacidade dos direitos fundamentais ou da liberdade face aos deveres fundamentais, uma vez que estes ainda servem, se bem que indirectamente, o objectivo constitucional da liberdade. (Ibid., pp. 119-120).

Assim, defende-se que a todos os direitos apresentam-se correlatos e necessários deveres constitucionais, de modo que não se imagina o desenvolvimento de um pensamento jurídico que não leve também em consideração essa dupla face interligada e conexa de preceitos, estejam ou não explícitos nos princípios, regras e valores constitucionais. Crê-se que os direitos têm por fundamento ético-jurídico os deveres e como fundamento histórico-social as necessidades.

De uma forma mais clara ainda: a violação dos deveres fundamentais, ou das disposições que venham a afastar, ou prejudicar a realização deles (e dos correlatos direitos fundamentais, direta ou indiretamente), na melhor medida, tem como consequência a mesma dimensão daquela decorrente de violação dos direitos fundamentais.

Sobre todas essas considerações, a amálgama se faz com a ponderação da dignidade da pessoa humana, que deve ser tida como vetor de determinação para a proteção de direitos e deveres fundamentais. 
É certo que a dignidade humana não foi incluída no rol dos direitos e das garantias fundamentais, mas, pela primeira vez na história legislativa pátria, o constituinte de 1988 inseriu-a como princípio fundamental, verdadeiro alicerce da ordem jurídica democrática. Igualmente relevante destacar que em nossa compreensão não há um direito fundamental à dignidade da pessoa humana como algo que possa ser objeto de concessão pela ordem estatal ou comunitária. Ancorado no entendimento do Tribunal Constitucional Espanhol, Fernandez Segado destaca que "si es claro que en nuestro ordenamiento constitucional [também ao brasileiro] la dignidade de la persona no puede ser entendida como derecho fundamental, no lo es menos que la dignidad puede ser considerada como la fuente de todos los derechos" (FERNANDES SAGADO, 2006, pp. 25-26). Portanto, a dignidade da pessoa humana precisa ser analisada e considerada como mandado de otimização, ordenando algo que deva ser realizado na melhor medida possível frente às possibilidades fáticas e jurídicas. Defendemos abertamente que "a dignidade da pessoa humana atua como elemento fundante e informador de todos os direitos, deveres e garantias fundamentais (explícitas ou implícitas) do sistema vigente, vinculando e obrigando todas as ações (positivas e de abstenção), privadas ou públicas". Ou, como expressamente reconhece Adolfo Bidart (antes referido), "os direitos e deveres fundamentais (aí inclusos os de o Estado agir positivamente) estão postos na mesma hierarquia constitucional, concluindo que os direitos humanos em cada homem requerer, para sua efetiva existência, igual fundamento ou base, de deveres de igual hierarquia e significação" (PEREIRA; FISCER, 2018 pp. 53 e 55).

\section{OS FUNDAMENTOS DAS OBRIGAÇÕES PROCESSUAIS PENAIS POSITIVAS NO ÂMBITO DAS CORTES SUPRANACIONAIS DE PROTEÇÃO}




\section{DOS DIREITOS HUMANOS E A REPERCUSSÃO NO ORDENAMENTO INTERNO BRASILEIRO}

São inúmeros os precedentes das cortes supranacionais a respeito da garantia dos direitos humanos no sentido de existir uma obrigação de as autoridades públicas responsáveis pela investigação e/ou persecução penal conduzirem procedimentos adequados, completos e eficazes, na tentativa de responsabilização dos autores dos delitos (obrigação "de meio"). Em síntese, sempre estiveram em voga perante as cortes supranacionais (o que pouco se divulga) a proteção dos interesses das vítimas, seus parentes ou coletividade em geral. Isso não poderia nem deveria causar maiores indagações, pois os direitos fundamentais a serem observados não estão, exclusivamente, na esfera daqueles relacionados com os autores de infrações que atinjam interesses dos demais em sociedade.

Deixamos bem expresso que essa perspectiva internacional gera efeitos significativos no quadro legal nacional ao ensejar preocupação com a eficácia da jurisdição penal e a proteção da vítima.

Deixamos indelevelmente assinalado na obra já referida alhures - para que não pairem dúvidas eventuais acerca dessa questão - que,

partindo da noção dos direitos fundamentais como objeto indispensável de proteção criminal (pela perspectiva integral dos direitos fundamentais), tais obrigações processuais são extraídas não apenas de disposições específicas, relativas à proteção dos direitos à vida, integridade física e psíquica, liberdade individual, vida privada e familiar, mas também de cláusula genérica que exige dos países o respeito dos direitos de todos aqueles que estejam sob a jurisdição do Estado. São reconhecidas, assim, obrigações reais e positivas dos Estados membros, que consistem no dever de seus órgãos internos assegurar a salvaguarda desses direitos, prevenindo a violação e esclarecendo judicialmente o cometimento de fatos ilícitos, como forma de efetuar sua repressão, não apenas formal e simbólica, mas adequada e concreta. (Ibid., 2018 p.59). 
É essencial realçar ainda que ambas as convenções (Interamericana de Direitos Humanos e Europeia) possuem regras que impõem aos Estados signatários obrigações de respeitar e fazer valer os direitos e liberdades reconhecidos. São obrigações de dupla vinculação: negativas, vedando aos Estados a violação de Direitos Humanos; positivas, pois exigem das partes a adoção de medidas necessárias para tutelar esses direitos, impedindo a violação deles por terceiros e reprimindo eficazmente eventuais lesões a esses direitos.

Tais considerações vêm ao encontro do que corretamente destaca em doutrina nacional Luiz Carlos dos Santos Gonçalves, para quem "as ordens constitucionais de criminalização são um instrumento da Constituição para oferecer proteção adequada e suficiente a alguns direitos fundamentais, diante de lesões ou ameaças vindas de agentes estatais ou de particulares", bem assim que a proibição do retrocesso de direitos fundamentais encontra sede, dentre outros, "no princípio da proporcionalidade, compreendido como inclusivo da vedação à proteção insuficiente" (GONÇALVES, 2007, pp. 160 e 168).

Reafirmamos incondicionalmente que, naqueles casos em que se faça presente a denominada dignidade penal (conformidades constitucional e também convencional), o sistema penal deve ser visto como instrumento de tutela dos direitos e das liberdades públicas. Assim, pontuamos expressamente que se estabelece uma "complementação na relação possível entre direito penal e os direitos fundamentais, uma vez que esses últimos deixam de ser concebidos apenas como limites à atividade punitiva estatal, para serem entendidos também como fundamentos, enquanto objeto de defesa, da atuação penal e processual penal" (PEREIRA; FISCER, 2018 p.61).

Temos tranquilidade em afirmar que as cláusulas convencionais protetivas dos direitos fundamentais exigem dos sistemas jurídicos 
domésticos a condução de investigações aprofundadas, céleres e diligentes, tendo como finalidade a tentativa de esclarecer os fatos e punir os responsáveis ao final do processo (identificando-se nítida hipótese de prevenção geral). Portanto, fica muito claro que os deveres processuais positivos decorrem diretamente, como implicações imediatas, dos direitos humanos protegidos também nas Convenções.

Não custa relembrar (especialmente aos mais desavisados) que, conquanto as Convenções europeia e interamericana de
direitos humanos não mencionem explicitamente a vítima
dos crimes, na jurisprudência das respectivas cortes supra-
nacionais, sobretudo no âmbito do Tribunal de Estrasburgo,
mas também no Tribunal de San José, a tutela da vítima é
tema recorrente e digno da máxima atenção. Em particu-
lar, o reconhecimento das obrigações processuais penais
positivas relacionadas à tutela das pessoas ofendidas é
cada vez mais frequente nas sentenças da Corte europeia
de direitos humanos. (Ibid., 2018 p.61).

Refira-se ainda que, em ambas Cortes supranacionais, são encontrados julgados com expressa fundamentação no sentido de existir um dever de o Estado investigar e processar os responsáveis por violações de direitos humanos como única forma de evitar a impunidade, tentando-se evitar também a reiteração de condutas lesivas e o desamparo das vítimas e seus familiares.

O processo deve ser adequado e idôneo na busca do esclarecimento de crimes. Porém, não há como se visualizar um processo penal sem levar em consideração, necessariamente, (e daí a importância das considerações anteriores a respeito desse tema), os direitos e os deveres fundamentais de todos os envolvidos na esfera de responsabilização criminal. Mais objetivamente: o processo penal deve ser compreendido sempre como um instrumento de garantia dos imputados e também de busca da realização das consequências previstas na lei penal (daí a compreensão integral que se fala). 
Significa que, para cumprir com as exigências decorrentes da proteção de (todos) os direitos previstos convencionalmente, "os sistemas jurídico-penais internos devem predispor estrutura de atuação e mecanismos adaptados a prevenir, coibir e sancionar efetiva e eficazmente as lesões verificadas" (Ibid., 2018 p.82).

É que,

uma vez constatada a possibilidade concreta de ofensas a direitos penalmente tutelados pelas convenções internacionais de direitos humanos, é necessário que as autoridades jurisdicionais e de polícia busquem efetivar a punição dos autores de delitos, mediante a identificação adequada do fato e dos responsáveis em procedimento conduzido de forma aprofundada, diligente e ágil, caracterizado por um esforço autêntico e aplicado na reconstrução dos fatos e na identificação das responsabilidades.(Ibid., 2018 pp.82-83).

Exatamente por conta dessas questões e decisões das cortes supranacionais é que, em âmbito nacional, jurisprudencialmente, estabeleceu-se como requisito fundamental para haver o denominado Incidente de Deslocamento de Competência "IDC a "demonstração inequívoca da total incapacidade das instâncias e autoridades locais em oferecer respostas às ocorrências de grave violação aos direitos humanos", sendo que "no momento do exame dessa condição devem incidir os princípios da proporcionalidade e razoabilidade, estes que, embora não estejam expressamente positivados, já foram sacramentados na jurisprudência pátria". A $3^{\text {a }}$ Seção do STJ explicitou que os requisitos do incidente de deslocamento de competência são três": a) grave violação de direitos humanos; b) necessidade de assegurar o cumprimento, pelo Brasil, de obrigações decorrentes de tratados internacionais; c) incapacidade "oriunda de inércia, omissão, ineficácia, negligência, falta de vontade política, de condições pessoais e/ou materiais etc. "de o Estado-Membro, por suas instituições e autoridades, levar a cabo, em toda a sua extensão, a persecução penal (IDC n. 1/ PA, Relator Ministro Arnaldo Esteves Lima, julgado em 8.6.2005, 
DJ 10.10.2005)", com especial referência no sentido de que para haver o deslocamento

\begin{abstract}
deve haver demonstração inequívoca de que, no caso concreto, existe ameaça efetiva e real ao cumprimento de obrigações assumidas por meio de tratados internacionais de direitos humanos firmados pelo Brasil, resultante de inércia, negligência, falta de vontade política ou de condições reais de o estado-membro, por suas instituições e autoridades, proceder à devida persecução penal (CRUZ, 2014).
\end{abstract}

Por todas essas razões é que sustentamos, em apertada síntese, que

as obrigações processuais penais positivas podem ser caracterizadas como um dever imposto aos Estados Partes de conduzir procedimento investigativo eficiente e processo penal apto a assegurar o acertamento dos fatos ilícitos e a punição dos eventuais autores, sob pena de violação concreta dos dispositivos das convenções regionais de direitos humanos que estipulam a salvaguarda dos direitos fundamentais envolvidos nas práticas ilícitas. (PEREIRA; FISCER, 2018, p.85).

\title{
5 A DUALIDADE ESTRUTURADA E INDISSOCIÁVEL DAS GARANTIAS SUBJETIVAS E OBJETIVAS DO PROCESSO E O PRINCÍPIO DA CELERIDADE
}

Em terras brasileiras, normalmente a abordagem que é feita, quando se fala de processo penal - e das respectivas garantias que o circundam e sustentam - é que estaria associado à necessidade de proteção exclusivamente dos direitos fundamentais do réu. Entretanto, destacamos na obra em referência no presente texto que os interesses compreendidos no complexo procedimento processual penal se dividem em dois grupos (que se complementam entre si): um relacionado ao esclarecimento dos fatos e da correta prestação jurisdicional; outro, relativo aos direitos subjetivos, de defesa e de dignidade dos imputados. 
É com base nessa dualidade de significados das garantias do processo que costuma se identificar na doutrina uma duplicidade de perspectivas nos dispositivos que orientam a disciplina da jurisdição penal.

As garantias objetivas são aquelas relativas à correta atuação da jurisdição no processo. Já as garantias subjetivas estão relacionadas à tutela daquelas que são submetidos ao processo.

É preciso deixar claro que não há dúvidas que as convenções internacionais explicitamente impõem a preservação das garantias processuais sob a ótica da proteção dos direitos individuais dos processados. Entretanto, em sentido complementar, destacamos que "a perspectiva do direito interno não se limita apenas a defender os interesses subjetivos das pessoas submetidas ao processo, mas volta-se também a resguardar o correto desempenho do poder jurisdicional" (Ibid., 2018, p. 94), impondo-se uma verdadeira salvaguarda do processo como instrumento relevante na busca da justiça.

O ponto central que precisa ser enfatizado é que nenhuma das perspectivas de proteção pode excluir a outra. Não há nenhuma antítese entre as garantias da jurisdição e a exigência de duração razoável do processo, muito menos uma tentativa de "limitar" as garantias processuais subjetivas. O que se defende é que deve haver uma aplicação equilibrada desses princípios (PEREIRA; FISCHER, 2018, p. 97).

Portanto, e voltando novamente às nossas considerações expressas,

o abuso, o excesso ou o descomedimento na utilização das garantias e estratégias processuais que podem gerar conflito entre forças com sentidos opostos na dinâmica processual, e, com isso, a necessidade de se equilibrar concretamente esses valores mediante o uso de técnica embasada na ponderação, justamente porque desbordaram da finalidade de justiça e correção na atuação jurisdicional. (Ibid., p.99). 
Como destacam Pacelli e Fischer,

\begin{abstract}
o princípio da ampla defesa não se compatibiliza com o que denominamos de abuso de defesa. O juiz não pode ser um mero espectador da vontade das partes, ficando inerte diante de fatos que, à evidência, dificultem a aplicação da Lei e que possam gerar a ineficiência (impunidade) do que já foi decidido pelo Poder Judiciário. Na condição de fiscal do correto andamento do processo (devido processo legal art. $5^{\circ}$, LIV, CF), o juízo não pode permitir que atos camaleônicos embasem pretensão de amparo à suposta ampla defesa quando disso não se tratar. Não há como estabelecer uma fórmula para definição de estar ou não havendo o que chamamos de abuso de defesa. Só o caso concreto poderá ensejar a ponderada avaliação a ser feita pelo Poder Judiciário (PACELLI; FISCHER, 2018).
\end{abstract}

Portanto, há se buscar o equilíbrio entre todos os princípios para evitar que, em determinadas situações, o uso das garantias subjetivas sejam desvirtuadas para o fim de apenas dilatar o curso procedimental, evitando-se uma decisão justa de mérito (quando não a prescrição, tema adiante abordado).

\title{
5.1 Dois casos concretos decididos no âmbito da CIDH
}

No Caso Myrna Mack Chang c. Guatemala, no âmbito da Corte Interamericana de Direitos Humanos (Sentença de 25.11.2003, série $C, n^{\circ} 101$ ), notadamente entre os parágrafos 204 e 211 do julgado, encontram-se preciosidades argumentativas que pouco são noticiadas de forma mais clara no Brasil.

Trata-se de um caso envolvendo uma vítima de homicídio (Myrna Mack Chang) ocorrido em 11 de setembro de 1990, decorrente de uma operação de inteligência militar. Firmou-se explicitamente que o Estado da Guatemala

no ha utilizado todos los medios a su disposición para realizar una investigación seria y efectiva que sirva de base 
para el esclarecimiento completo de los hechos, el procesamiento, juzgamiento y sanción de todos los responsables, tanto autores materiales como intelectuales, dentro de un plazo razonable.

Reconheceu-se que a adoção de procedimentos recursais descabidos e protelatórios no âmbito do processo penal

aunque permisible por la ley, ha sido tolerada por las autoridades judiciales. Este Tribunal considera que el juez interno, como autoridad competente para dirigir el proceso, tiene el deber de encauzarlo, de modo a que se restrinja el uso desproporcionado de acciones que pueden tener efectos dilatórios. (parágrafo 207).

\section{Afirmou-se que essa}

manera de ejercer los medios que la ley pone al servicio de la defensa ha sido tolerada y permitida por los órganos judiciales intervinientes, con olvido de que su función no se agota en posibilitar un debido proceso que garantice la defensa en juicio, sino que debe además asegurar en un tiempo razonable el derecho de la víctima o sus familiares a saber la verdad de lo sucedido y a que se sancione a los eventuales responsables (parágrafo 209).

Considerou-se, ainda, que

los jueces como rectores del proceso tienen el deber de dirigir y encausar el procedimiento judicial con el fin de NO sacrificar la justicia y el debido proceso legal en pro del formalismo y la impunidad. De este modo, si las autoridades permiten y toleran el uso de esta manera de los recursos judiciales, los transforman en un medio para que los que cometen un ilícito penal dilaten y entorpezcan el proceso judicial (parágrafo 210), concluindo-se que esse tipo de procedimento conduce a la violación de la obligación internacional del Estado de prevenir y proteger los derechos humanos y menoscaba el derecho de la víctima y de sus familiares a saber la verdad de lo sucedido, a que se identifique y se sancione a todos los responsables y a obtener las consecuentes reparaciones. (parágrafo 211).

Em sentença de 15 de março de 2018, o Brasil sofreu outra con- 
denação da CIDH, no conhecido Caso Vladimir Herzog ${ }^{8}$. A Corte analisou a responsabilidade internacional do Estado com base nas obrigações internacionais derivadas da Convenção Americana e da Convenção Interamericana para Prevenir e Punir a Tortura, relativamente à ausência de investigação, julgamento e eventual punição dos responsáveis pela tortura e assassinato de Vladimir Herzog. Concluiu-se - e nesse ponto a questão importante que reflete no tema ora sob debate - que a obrigação de investigar e, nesse caso, julgar e punir os responsáveis adquire particular importância ante a gravidade dos delitos cometidos e a natureza dos direitos lesionados. Mais que isso, reconheceu-se que o Brasil assumiu obrigações internacionais de prevenir e punir crimes dessa natureza, reafirmando que "o Estado deve conduzir de maneira eficaz a investigação penal dos fatos do presente caso, a fim de esclarecê-los, determinar as respectivas responsabilidades penais e aplicar efetivamente as sanções e consequências que a lei disponha" (parágrafo 371).

Portanto, para cumprir os mandados impostos constitucionalmente, e as obrigações assumidas internacionalmente, é dever do Estado brasileiro adotar todas as medidas essenciais para que haja uma adequada tipificação de fatos que necessitem a proteção na seara penal, bem assim que sejam adotadas providências para uma efetiva, célere, eficaz e eficiente apuração desses fatos noticiados, responsabilizando-se os agentes criminosos.

\subsection{A prescrição como violação das obrigações processuais penais positivas}

Os mecanismos de prescrição que simplesmente impedem a reação sancionatória exigida perante ofensas a bens jurídicos fun-

8 Disponível em: http://www.corteidh.or.cr/docs/casos/articulos/seriec_353_por.pdf Acesso em: 17 dez. 2018. 
damentais, em razão da desmedida duração do processo, contrariam a efetividade da resposta penal necessária segundo os padrões internacionais de tutela dos direitos humanos. Tanto a Corte Europeia de Direitos Humanos como a Corte Interamericana reconhecem a incompatibilidade do esvaziamento da prestação jurisdicional em razão de transcurso de prazo prescricional, quando se tratar de graves violações do direito à vida, e quando se estiver diante de tortura e tratamentos desumanos. É importantíssimo deixar bem claro, desde logo, que esses entendimentos não significam um atestado genérico de incompatibilidade da previsão do instituto da prescrição, pois é fundamental existir o instituto como preservação da segurança jurídica, devendo cada ordenamento interno fazer a sua regulamentação quanto ao tema. Em verdade, o problema não está na prescrição em si, mas na falta de diligências, ou celeridade nas apurações, ou de processos sancionatórios decorrente de atrasos, ou delongas injustificáveis.

Como expressamente manifestamos, "é possível se reconhecer um princípio geral de que a duração razoável do conjunto do procedimento penal é requisito inerente às exigências de efetividade e adequação da reação estatal perante violação dos direitos humanos, inclusive como forma de evitar a descontinuidade do procedimento penal pela prescrição" (PEREIRA; FISCER, 2018, p.112), sendo que

a exigência de presteza no prolongamento do processo na entrega definitiva da resposta penal deve ser compreendida como uma garantia direcionada à preservação de todos os interesses envolvidos no juízo, o que inclui o acusado, as vítimas do delito, e a própria confiança pública no Estado de Direito, o que depende, decisivamente, da eficiência e da qualidade do exercício da função jurisdicional, principalmente quando se estiver diante de ofensa a direitos individuais tutelados internacionalmente. (Ibid., p.113). 


\section{EXIGÊNCIAS PROCESSUAIS COMO OBRIGAÇÕES DE MEIO E NÃO DE RESULTADO}

Muito importante ainda explicitar que as obrigações processuais penais positivas não se qualificam como de resultado, mas sim de meio. Assim, há se direcionar os meios de investigação para a apuração dos fatos de forma eficiente, tendo uma aptidão para o esclarecimento dos fatos e imposição de penas aos eventuais responsáveis.

A exigência, portanto, é de que as autoridades realizem o percurso necessário e adequado para a pesquisa e coleta da prova que tenham condições de, ao final, revelar como os fatos aconteceram e, se for o caso, a partir do que apurado, sejam os autores dos ilícitos responsabilizados criminalmente em tempo razoável. Por outro lado,

as exigências processuais relacionadas às garantias de defesa dos imputados podem, com base na mesma lógica acima, ser consideradas como obrigações de resultado, indicando que não basta apenas um esforço ou comprometimento dos agentes públicos e sujeitos processuais na sua preservação, é necessário que se alcance efetivamente o standard de proteção imposto pelas garantias defensivas e de dignidade humana. (Ibid., 2018, p.148).

Reafirmamos sempre a necessidade de se manter o equilíbrio no sistema de justiça penal entre os direitos de defesa e da dignidade humana. Não há como imaginar um sistema de justiça de proteção aos direitos e liberdades fundamentais sem que se faça, ao mesmo tempo, a devida proteção de todos os demais direitos previstos constitucional e convencionalmente.

\section{CONSIDERAÇÕES FINAIS}

Não temos dúvidas em (re)afirmar que é preciso superar a ideia de que o Estado deve ter apenas limites em sua atuação. Há imposições de ações positivas (garantismo positivo). A justiça penal 
reclama uma efetiva atuação do Estado para a proteção de todos os direitos fundamentais. Há, sim, uma dupla função de proteção de direitos humanos: "proteger os direitos do homem está umbilicalmente ligado à adoção de ações positivas direcionadas a prevenir e sancionar com eficiência as ofensas que eventualmente lhes podem ser direcionadas, buscando-se sempre um equilíbrio nas relações entre todos os direitos e deveres fundamentais" (Ibid., p.151). Desse modo, para a (e na) proteção dos direitos e das garantias fundamentais (individuais e coletivas) e na exigibilidade do cumprimento dos deveres fundamentais, há de se observar que todos os princípios que compõem o ordenamento jurídico (e não apenas aqueles de proteção de direitos individuais de primeira geração) são verdadeiras guias na dinâmica e harmônica configuração (na melhor medida possível) de todos os bens e valores protegidos constitucionalmente.

Portanto, é essencial visualizar que os deveres de proteção (garantismo positivo) decorrem do conteúdo objetivo dos direitos fundamentais, impondo-se uma obrigação de proteção desses direitos protegidos constitucional e convencionalmente. Significa que

nos termos aqui utilizados, e tendo por inspiração principal a jurisprudência mais desenvolvida do Tribunal Europeu de Direitos Humanos, trata-se de verdadeira obrigação imposta aos Estados-Membros de conduzir mecanismo penal apto ao esclarecimento dos fatos lesivos aos interesses das vítimas, havendo precedentes na mesma linha de inúmeros julgados da Corte Interamericana de Direitos Humanos. (Ibid., p.154).

Procurou-se sustentar, de uma forma sintética - diante do espaço disponível -, que tanto a Convenção americana como a Convenção europeia de direitos humanos possuem inúmeras obrigações positivas (deveres) que consistem em exigências aos Estados Partes em adotar as medidas necessárias e adequadas para conferir efetividade à tutela de todos os direitos protegidos. De uma maneira mais objetiva e direta, assenta-se que os deveres 
processuais positivos decorrem diretamente, como implicações imediatas, dos direitos humanos protegidos nas Convenções, conforme inúmeros julgados indicados na obra de referência.

Com base em várias decisões de jurisprudências das Cortes supranacionais, demonstrou-se que a tutela da vítima não é apenas um tema recorrente, como central, exatamente porque existe a noção (não tão clara ainda em terras brasileiras) de que, no âmbito criminal, o processo deve ser adequado e idôneo no esclarecimento dos fatos criminais. Daí a razão que afirmarmos que não há como compreender o processo penal sem levar em consideração os direitos e deveres fundamentais, pois, "ao contrário do que procuram sustentar alguns posicionamentos, a compreensão não pode ser parcial, pelo prisma exclusivo dos direitos fundamentais do investigado ou processado".

Assim, as obrigações processuais penais positivas são deveres impostos aos Estados para que conduzam procedimentos investigativos e processo penal aptos a assegurar a punição eventual dos autores das práticas ilícitas.

Encerrando, reiteramos que os direitos humanos e as garantias individuais de cada pessoa requerem, para sua efetiva existência, igual fundamento ou base constitucional de deveres de igual hierarquia e significação. Portanto, os Estados devem agir sem excessos nem deficiências, buscando a equalização e proteção na máxima medida possível de todos os direitos protegidos constitucional e convencionalmente. 
POSITIVE PENAL PROCEDURES DUTIES:

ACCORDING TO THE PRECEDENTS OF THE

EUROPEAN COURTS AND INTER-AMERICAN

COMMISSION ON HUMAN RIGHTS

\section{ABSTRACT}

It will be demonstrate that there are precedents of the supranational Courts of human rights that, by interpretation of the respective conventions, recognize the existence of expressed of duties of the States to adopt all the measures for the investigation of the illicit facts committed, always respecting fundamental rights. The purpose is to demonstrate that precedents recognize that it is also essential to consider the plexus of protected guarantees of victims and of the collectivity in general.

Key-words: Supranational courts of human rights. Protected guarantees of victims. Duties of the States.

\section{REFERÊNCIAS}

BERNAL PULIDO, Carlos. El derecho de los derechos. Bogotá: Universidad Externado de Colombia, 2005.

BIDART, Adolfo Gelsi. De Derechos, deberes y garantías del hombre común. Montevideo-Buenos Aires: Julio Cesar Faira Editor, 2006.

CANOTILHO, José Joaquim Gomes. Constituição Dirigente e Vinculação do Legislador. 2. ed. Coimbra: Coimbra Editora, 2001.

COELLO NUÑO, Ulises. La Constitución Abierta como categoría dogmática. Barcelona: J. M. Bosch, 2005.

Corte interamericana de direitos humanos caso Herzog e outros VS. Brasil sentença de 15 de março de 2018. Disponível em: http:/ /www.corteidh.or.cr/ docs/casos/articulos/seriec_353_por.pdf Acesso em: 17 dez. 2018.

FERNANDEZ SEGADO, Francisco. Constitución y Valores: La dignidad de la 
Persona como valor supremo del Ordenamiento Jurídico. In: PALESTRA CONFERIDA NO MÓDULO V DO CURSO DE DIREITO CONSTITUCIONAL. Porto Alegre: 31 mar. 2006, Escola da Magistratura do Tribunal Regional Federal da $4^{a}$ Região., p. 25-26.

FERRAJOLI, Luigi. Derechos y garantias: la ley del más débil. 4. ed. Madrid: Trotta, 2004.

Garantismo: una discusión sobre derecho y democracia. Madrid: Trotta, 2006.

GONÇALVES, Luiz Carlos dos Santos. Mandados expressos de criminalização e a proteção de direitos fundamentais na Constituição brasileira de 1988. Belo Horizonte: Fórum, 2007.

Incidente de Deslocamento de Competência n. 5-PE, STJ, 3ª Seção, unânime, Rel. Min. Rogério Schietti Cruz, julgado em 13.8.2014, publicado no DJ em $1^{\circ} .9 .2014$.

NABAIS, José Casalta. O Dever Fundamental de Pagar Impostos. Coimbra: Almedina, 1998, p. 64.

NOVAIS, Jorge Reis. As restrições aos direitos fundamentais não expressamente autorizadas pela Constituição. Coimbra: Coimbra, 2003. PACELLI, Eugênio; FISCHER, Douglas. Comentários ao Código de Processo Penal e sua jurisprudência, 10. ed., 2018.

PEREIRA, Frederico Valdez; Fischer, Douglas. As Obrigações Processuais Penais Positivas Segundo as Cortes Europeia e Interamericana de Direitos Humanos. Porto Alegre: Livraria do Advogado, 2018, p. 85. PRIETO SANCHÍS, Luis. Constitucionalismo y garantismo. In: CARBONELL, Miguel; Salazar, Pedro. Garantismo: estúdios sobre el pensamiento jurídico de Luigi Ferrajoli. Madrid: Trotta, 2005.

Revista de Doutrina 4. Região, v. 28, p. 1, 2009. Também em Revista do Núcleo Criminal da PRR $1{ }^{\text {a }}$ Região - Brasília, v. Ano 2.

ZAGREBELSKYY, Gustavo. El derecho dúctil. Ley, derechos, justicia. 6.ed. Madrid:Trotta, 2005, p. 95. 